\title{
Comportamiento político en la tensión libre comercio-proteccionismo: Caso de dumping LAICA-La Maquila S.A.
}

Recibido: 26 de agosto 2019

Revisado: 11 de octubre 2019

Aprobado: 10 de noviembre 2019

Julia Paola Barrantes Aguilar

Costarricense. Licenciada en Ciencias Políticas por la Universidad de Costa Rica. Labora como editora de la revista e-Agronegocios.

Correo electrónico: jpbarrantes91@gmail.com

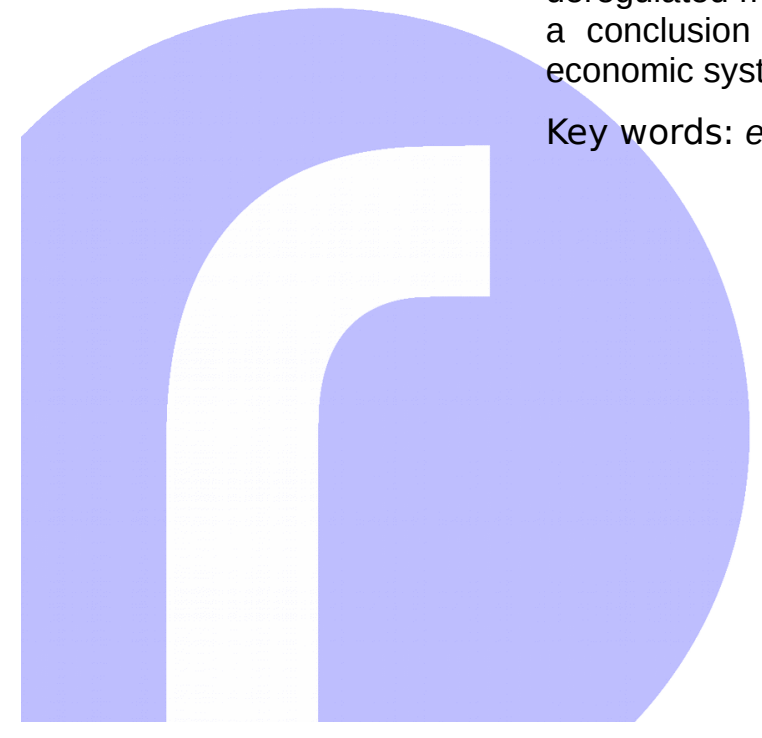

https://revistas.uned.ac.cr/index.php/rupturas/ (c) (1) (2) países.
Resumen: El objetivo es analizar el comportamiento político del sector azucarero costarricense en la tensión libre comercio-proteccionismo, en el caso de dumping entre LAICA y La Maquila Lama S. A., mediante entrevistas semiestructuradas y monitoreo de medios de comunicación; se realiza un análisis de coyuntura del caso contemplando las categorías de análisis: acontecimientos, actores, escenarios, tácticas y estrategias. Se identifica que la discusión entre el libre comercio y el proteccionismo es imaginaria, en el tanto estos dos modelos son, en principio, modelos teóricos de economía. En la práctica, no existe ninguna economía de mercado completamente desregulada ni tampoco ninguna completamente protegida. Por ello, una conclusión para este estudio es que ambos modelos coexisten dentro del sistema económico y en diferentes niveles dentro de las economías de los

Palabras clave: política económica; política comercial; industria alimentaria

\section{Political behavior in free trade-protectionism tension: LAICA-La Maquila Lama dumping case}

Abstract: The objective is to analyze the political behavior of the Costa Rican sugar sector in the free trade-protectionist tension, in the case of dumping between LAICA and La Maquila Lama, through semi-structured interviews and media monitoring, a joint analysis of the case is carried out contemplating the categories of analysis: events, actors, scenarios, tactics and strategies. It is identified that the discussion between free trade and protectionism is imaginary; in the meantime, these two models are, in principle, theoretical models of economics. In practice, there is no fully deregulated market economy or any fully protected economy. For this reason, a conclusion for this study is that these two models coexist within the economic system and at different levels within the economies of the countries.

Key words: economic policy; trade policy; food industry 


\section{Introducción}

\section{El acto de producir es un acto político}

Uno de los debates más acalorados a nivel internacional se libra alrededor de las ventajas y desventajas de la liberalización comercial, es decir, la implementación de políticas para reducir progresivamente las barreras arancelarias y no arancelarias que los distintos países o bloques económicos imponen al libre tránsito de mercancías, personas y capital, a escala mundial (Fernández 2004,3$)$. Discursivamente, la mayoría de los gobiernos consideran la meta de la liberalización como un factor positivo e incuestionable para alcanzar el desarrollo económico. Con frecuencia, se justifica esta práctica aperturista por medio de un conjunto de afirmaciones teóricas, las cuales exponen que, si se permite que los mercados funcionen sin restricciones ni barreras, se atenderán de manera óptima todas las necesidades económicas globales, utilizando recursos económicos de manera eficiente y produciendo pleno empleo (Shaikh 2004,1). Algunos actores clave del comercio internacional, incluso, garantizan que el comercio es la forma más segura para promocionar un crecimiento económico favorable a los pobres (Moore en Shaikh 2004,1), al punto de considerarlo como un principio casi "sagrado" (Krugman 1987, 131). En efecto, existe algún grado de consenso con estas afirmaciones entre los gobiernos de muchos Estados, el cual se ha reflejado en convenios internacionales como el Tratado de Marrakech, creado por la Organización Mundial del Comercio (OMC), como principal promotor de la reducción de barreras arancelarias y no arancelarias al comercio internacional.

Sin embargo, la Ronda de Doha para el Desarrollo -la primera ronda de negociación destinada a una completa liberalización del comercio internacional tras crear la OMC- no ha logrado concluir después de trece años de negociación. Este bloqueo en la agenda global del libre comercio se debe al límite que países miembros han encontrado respecto a su disposición y capacidad de reducir barreras. En el núcleo de este bloqueo se encuentra la agricultura, a la cual se pretende eliminar subvenciones a la exportación, reducir ayudas internas (consideradas como distorsiones de comercio) y atender preocupaciones no comerciales, como la seguridad alimentaria y el desarrollo rural (OMC 2018). En este contexto, la dinámica real del funcionamiento de las economías globalizadas deja entrever que la postura del libre comercio se

1. Se utiliza este término para facilitar la comprensión de la discusión; sin embargo, se entrecomilla debido a la necesidad de discutir sobre cómo este término puede autoposicionar a los países en un rol de dependencia, partiendo del hecho de que el lenguaje construye la realidad. enfrenta constantemente a resistencias. El proteccionismo es una faceta vigente entre países o bloques económicos que buscan defender sus intereses nacionales de desarrollo a costas de una mayor liberalización comercial (Fernández 2004, 3). Hoy por hoy, son los países industrializados y económicamente desarrollados los que tienen estructuras económicas más proteccionistas y los países "subdesarrollados"1 son los que, a escala mundial, tienden a buscar el desarrollo de una economía más abierta (Fernández 2004, 4). Un ejemplo es que, a pesar de la firma de acuerdos comerciales en ambas situa- 
ciones (países industrializados y "subdesarrollados"), persisten mecanismos de protección que impiden la entrada del azúcar costarricense a mercados internacionales como el mexicano y el canadiense (Carlos Molina, comunicación personal, 5 de febrero de 2018; Fernández 2004, 58).

La paradoja del proceso de liberalización global es que los Estados siempre han procurado defender su producción nacional de las importaciones como mecanismo para promover desarrollo, pero, simultáneamente, pretenden abrir los mercados de otros países a sus productos, para reducir costos y también promover desarrollo (Fernández 2004, 29). Es decir, a pesar de que el libre comercio se considera discursivamente como la mejor opción para repartir la riqueza en el mundo, en su ejercicio, el poder político y económico en la nación también busca definir parámetros regulatorios favorables a sectores económicos clave considerados de importancia para promover el desarrollo nacional.

Esta es el motivo por el que la discusión sobre liberalización comercial como modelo de desarrollo económico no es completamente estatal. Los Estados no definen la política comercial de los países aislados del entramado de actores involucrados en esta discusión, eso significa que el entendimiento de la discusión entre libre y proteccionismo se complejiza al contemplar el comportamiento político de todos los actores vinculados, resguardando sus diferentes tipos de intereses, contando con distintos recursos para lograrlo y con diversas capas de institucionalidad activadas alrededor del mismo foco. Por ello, no se puede comprender la relación entre comercio y desarrollo sin una desagregación del sector económico que busca ser liberalizado o protegido. Esto incluye comprender cómo funcionan estos sectores, identificar las cadenas de producción involucradas, los actores participantes, los intereses y las relaciones de fuerza establecidas en cada relación comercial particular.

Paralela a esta discusión "mayoritariamente estatal", hay que comprender el impacto comercial producido por el fenómeno de la transnacionalización de las economías. Después de la Segunda Guerra Mundial, ocurrieron cambios significativos en el ordenamiento económico mundial que afectaron las economías locales y a las sociedades en general, y que, de una manera casi total, pusieron en riesgo al sector agrícola de los países "subdesarrollados".

Esta reestructuración parte del principio de integración profunda del mercado internacional (Fernández 2004, 25); pero no entre países, sino entre empresas transnacionales. De esta dinámica, se desprende el caso particular de estudio del conflicto entre La Maquila Lama (a partir de ahora, LML) y la Liga Agrícola Industrial de la Caña de Azúcar (LAICA) por el mercado del azúcar.

Las empresas transnacionales constituyen la nueva potencia económica, caracterizada porque "su campo de inversiones y vinculaciones comerciales necesariamente debe darse a escala mundial" (Fernández 2004, 25). Esto implica que se entienda la economía del mundo como un todo (Fernández $2004,26)$ y el conjunto de las regulaciones del comercio internacional, las barreras nacionales al comercio de ciertos insumos o productos se consideren como frenos al desarrollo de sus actividades comerciales. Esta economía del 
mundo, según el autor, forma parte de un sistema social y político global, cuyas divisiones geográficas fundamentan y condicionan, simultáneamente, a esa economía. Las presiones en cuanto a reestructurar la política económica de los países para consolidar una economía globalizada se imponen desde organizaciones internacionales como la OMC, el Banco Mundial, el Fondo Monetario Internacional e incluso mediante agencias de cooperación internacional. Sin embargo, los intereses nacionales se incrementan "en aras de resguardarlos frente a la evolución de esa economía globalizada" (Fernández 2004, 25).

Es importante considerar que el capital transnacional no tiene compromisos con las necesidades particulares de las regiones donde se instala, ya que su vocación es universal. Sin embargo, las corporaciones transnacionales requieren el consentimiento político de los países para su funcionamiento en cada economía particular. De este hecho, se derivan las dos posturas que, en teoría, se contraponen: el libre comercio, el cual deviene una estructura internacional que pretende la unificación del mercado mundial y, por ende, la reducción de los obstáculos nacionales a las inversiones transnacionales; y el proteccionismo que considera resguardar alguna rama de producción, sector comercial o empresa, de las importaciones que entran al país en condiciones diferentes a las nacionales, por ejemplo, estructuras de costos de producción más elevados (Fernández 2004, 121).

El libre comercio es uno de los cimientos más importantes del neoliberalismo, entendido como el proyecto político de una élite económica mundial que procura estabilidad y previsibilidad en sus transacciones globalizadas. Esta postura considera que, para lograr un desarrollo económico, los países "subdesarrollados" deben eliminar las intervenciones estatales en el mercado. Sin embargo, algunos críticos señalan que, actualmente, el mundo está lejos de cumplir la teoría de ventajas comparativas y desnudan una serie de contradicciones en el sistema internacional que lo vuelven más complejo, por ejemplo, que los países industrializados lograron su desarrollo económico, en gran medida, por el proteccionismo comercial y la intervención estatal (Agosin y Tussie 1993, 25; Chang 2003; Stiglitz 2002). En palabras de Chang:

Cuando eran países en desarrollo, prácticamente ninguno de los países hoy desarrollados practicaba el libre comercio (ni una política industrial de liberalización como contrapartida doméstica) sino que promovía sus industrias nacionales mediante aranceles, tasas aduaneras, subsidios y otras medidas $(2003,1)$.

Precisamente, el crecimiento económico de estos países se debe a la protección de sus sectores más vulnerables y sensibles, como la agricultura. En la actualidad, la Unión Europea mantiene altos subsidios a la producción agrícola. Por ejemplo, durante décadas, Alemania blindó legalmente a su indus- 
tria azucarera, mediante cuotas de producción y el establecimiento de precios mínimos de la remolacha azucarera (Ulrich 2017); esta protección se redujo por la presión de países latinoamericanos productores de azúcar. ${ }^{2}$

El proyecto neoliberal ha sido ejecutado en la mayoría de los países en la región latinoamericana, no obstante, cada uno establece los límites y alcances de su lógica y funcionamiento. En Costa Rica, por ejemplo, existen oficinas que promueven la competencia ${ }^{3}$ por medio de la eliminación de restricciones y el libre comercio, inspirados en el principio de competitividad y eficiencia en la producción, es decir, postulados que indican que deben sobrevivir -únicamente- aquellas corporaciones, industrias, empresas o productores que sean lo suficientemente eficientes como para competir internacionalmente. La teoría no establece los parámetros de competición, ello implica que, según las posturas neoliberales, eficiente es aquella empresa que es competitiva con quien quiera dominar su mercado.

Estas dinámicas se encuentran inmersas en un sistema global, caracterizado por cambios tecnológicos y la aparición de competidores con mayor poder económico (Rosales 2009, 77), "lo que se ha traducido en drásticos cambios en la competitividad y una tendencia a estructurar la producción en torno a cadenas mundiales de valor" (Rosales 2009, 77). Con base en la idea de que la globalización es un proceso en el cual las cadenas de producción, industrialización y distribución se llevan a cabo a nivel mundial por corporaciones transnacionales, se infiere que las empresas nacionales deben competir con estas corporaciones mundiales y sobrevivir para ser consideradas eficientes; en caso contrario, no deberían existir. Es importante enfatizar que las implicaciones de esa lógica económica "incluyen, por ejemplo, drásticos cambios en el mapa mundial del intercambio comercial y las ventajas competitivas, así como nuevos ganadores y perdedores a nivel de zonas económicas, países, sectores productivos y empresas" (Rosales 2009, 77). El papel asumido por estos sectores productivos y empresas conlleva diferentes formas de ejercer el poder por parte de actores no estatales, lo que obliga a tratar la discusión entre libre comercio y proteccionismo tomando en cuenta la diversidad de actores no estatales que ejercen su poder político en estos procesos comerciales globalizados.

Por un lado, los promotores de la competencia impulsan el libre comercio como una vía para aumentar la cantidad de oferentes de un solo bien en un mismo mercado. Sin embargo, las importaciones, generalmente, provienen de un sistema transnacional de producción que profundiza, a escala mundial, la concentración de bienes de producción, aspecto contrario a los principios de la libre competencia. Esta es una de las paradojas más peligrosas del libre comercio, ya que los monopolios de producción de bienes sensibles y estratégicos pueden distorsionar los precios a su favor y hasta pueden provocar crisis económicas. El debate posterior es considerar el costo social de ser lo suficientemente competitivos. Por otro lado, desde el proteccionismo, se considera fundamental incluir los costos sociales de la eficiencia en el debate; además, en el análisis, se agregan otros aspectos más allá del precio, como la sostenibilidad ambiental a largo plazo, la generación de empleos directos e
2. Según la UNICEF (2003), "el nivel del apoyo financiero que otorgan los países de la OCDE a sus productores en el sector agrícola ha sido alto y aumentó (específicamente en la Unión Europea) a más de 250 mil millones de dólares en 2003 , resultando en una competencia desigual con los agricultores en los demás países".

3. Según Fernández (2004), "la orientación neoliberal se plasma también en la inclusión de principios de la doctrina neoliberal en el marco jurídico de Costa Rica, especialmente con la Ley de Promoción de la Competencia y Defensa Efectiva del Consumidor". 
indirectos, la soberanía alimentaria, es decir, la autonomía alimentaria de cada país frente a desastres naturales, entre otros. El proteccionismo tiene una característica fundamental: es nacional, local o regional e incluso sectorial; a diferencia del libre comercio, que se inspira en políticas mundiales, internacionales y globalizantes. Por lo tanto, el proteccionismo es una práctica contraria a la globalización, articula y resguarda las fuerzas de lo local o nacional frente a una lógica internacionalista que pretende la apertura irrestricta.

El sector agrícola en Costa Rica sufriría de cuantiosas pérdidas ante una apertura comercial irrestricta. Los sectores pequeños de productos agrícolas, por su frontera agrícola, la estructura política agraria del país y la escasa producción tecnificada y a escala, tendrían una probable desaparición. Según Fernández (2004), las consecuencias conexas de esta desaparición de pequeños productores a nivel económico y social son "la proletarización y aumento de las masas marginales en las ciudades, reconversión productiva, baja del nivel de vida, aumento de la dependencia externa, impacto negativo sobre la balanza de pagos derivado de la necesidad de la importación" (Fernández 2004,15). El sector agrícola en Costa Rica, al igual que en las otras economías latinoamericanas, tiene una relevancia económica en tanto representa un alto porcentaje del PIB y del sector exportador agrícola y agroindustrial. Además, la mayor cantidad de productores se encuentra en las zonas rurales del país, lo cual ofrece oportunidades de subsistir y generar empleo en áreas que, de por sí, tienen los índices más altos de extrema pobreza (UNICEF 2003). Según la UNICEF, el acuerdo DR-CAFTA despliega una situación desigual de competencia entre los productores de Estados Unidos y sus contrapartes en Centroamérica, ya que "los agricultores en Estados Unidos acceden a la competencia internacional apoyados por subsidios domésticos y de exportación, mientras sus contrapartes en Centroamérica no cuentan con dichas ventajas" (UNICEF 2003).

Se proyecta que una consecuencia de eliminar los aranceles es la entrada masiva de productos subsidiados. Por ende, el resultado serían precios bajos en bienes agrícolas sensibles (como arroz, maíz, frijoles, azúcar) para el consumidor final, lo cual si bien podría ser positivo para las familias consumidoras, incluso para las agricultoras, ya que los productores también son consumidores de bienes alimenticios de la canasta básica, se corre el riesgo de que una parte importante de la población que cultiva estos bienes localmente pierda su fuente de ingreso y su modo de vida vinculado a la tierra (UNICEF 2003). La reducción de empresas agrícolas de bienes sensibles podría representar una amenaza a la provisión de alimentos suficientes para todos los estratos de la población (UNICEF 2003) y perpetuar la dependencia de las importaciones de alimentos.

Estas son algunas de las razones por las que se duda de la apertura comercial del sector agrícola en países latinoamericanos, donde aún existen muchas familias que dependen de la actividad, a pesar de estar inmersos en olas de integración mundial del mercado; tales consideraciones también provienen de países altamente industrializados, pues los más desarrollados 
mantienen altos niveles de protección a su sector agrícola (Chang 2003,1). Por ejemplo, Estados Unidos conserva una política de producción agrícola fundamentada en una amplia base de subsidios, eso lo ha convertido en el principal productor y exportador de gran cantidad de bienes agrícolas y pecuarios. La Unión Europea también desarrolló una política proteccionista y de subsidio a la producción, cuyo objetivo era llegar al autoabastecimiento de productos de alimentación y romper con la dependencia de las importaciones (Fernández 2004, 54).

El autoabastecimiento alimentario es una de las razones de mayor relevancia para el proteccionismo comercial. En efecto, la OMC establece, dentro de su compendio de normas, la posibilidad de que las diferentes naciones instauren protecciones especiales a sectores que se consideren estratégicos. Una de las razones para considerar un sector estratégico es que los productos sean parte de la canasta básica de alimentación local, y su afectación por importaciones masivas cause un aumento de la vulnerabilidad de aquellas personas que dependen del abastecimiento de este tipo de alimentos, lo cual afectaría la soberanía alimentaria a largo plazo. En particular, estas medidas de protección se orientan a aquellos países que no tienen capacidad de sostener las importaciones de alimentos, debido a la inestabilidad en sus exportaciones (Fernández 2004,125).

Costa Rica, al igual que otros países latinoamericanos, es altamente dependiente de la producción agrícola para exportarla hacia Estados Unidos, ya que más del $40 \%$ de las exportaciones tienen ese destino, según el informe estadístico de la Promotora de Comercio Exterior de Costa Rica (Procomer).

\section{Gráfico 1. Principales regiones de destino de las exportaciones costarricenses, según participación del valor exportado.}

\section{PRINCIPALES REGIONES DE DESTINO}

PARTICIPACIÓN DEL VALOR EXPORTADO

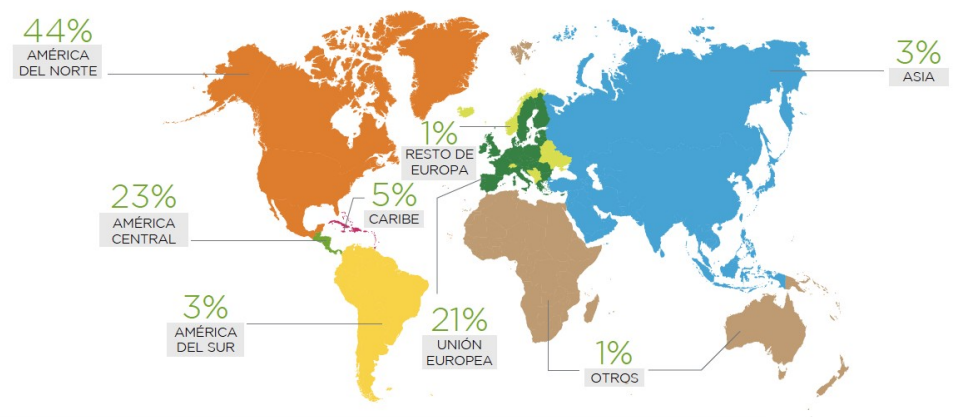

Fuente: Anuario estadístico PROCOMER $(2016,16)$.

No obstante, estos países mantienen políticas proteccionistas arancelarias y altos niveles de subsidios que procuran el autoabastecimiento, en la Unión Europea y Estados Unidos, "la política de subsidios agrícolas (...) alcanzó los 
228000 millones de dólares en 2017" (Castro 2016). De tal manera, las exportaciones de productos agrícolas o agroindustriales de Costa Rica y otros países latinoamericanos similares quedan excluidas de este mercado, por la imposibilidad de competir contra productos subsidiados.

A su vez, en estos países se encuentran las empresas exportadoras agrícolas más grandes del mundo, las cuales aumentan sus niveles de excedentes y requieren mercados internacionales donde colocarlos, por lo que tener el mercado latinoamericano libre de restricciones arancelarias resulta estratégico. Por eso es importante considerar el papel del Estado en los conflictos comerciales, a fin de cuentas, las decisiones que toma el Gobierno afectan, promueven o bloquean cierto flujo de negocios internacionales o nacionales. El poder político es decisivo para mantener protegido un sector agrícola específico, sin embargo, también es fundamental para reestructurar y desarticular las barreras que impiden el desarrollo de las corporaciones transnacionales dentro del territorio nacional. El debate político se concentra en decidir entre el proteccionismo o el libre comercio como modelo de desarrollo económico.

\section{Apartado metodológico}

Este es un estudio de caso, por lo que se realizó una investigación cualitativa debido a que se pretende describir el comportamiento político de diversos actores (individuales y colectivos) en los procesos de toma de decisiones relacionados con las políticas comerciales, como instrumento de política económica.

La delimitación temporal de la investigación responde completamente a la coyuntura en estudio. El corte temporal definido comprende el periodo 20142017, cuando comienza y finaliza el conflicto formal entre LAICA y LML. EI hecho o acontecimiento central que determina el inicio de la coyuntura es cuando comienzan las importaciones de azúcar de LML; y el que cierra la coyuntura son las resoluciones del Ministerio de Economía Industria y Comercio (MEIC) de la denuncia interpuesta por LAICA, en la cual alegaba prácticas de comercio desleal por parte de LML mediante dumping por el azúcar. Es un cierre metodológico, lo que significa que las prácticas comerciales, tácticas e intereses de los actores pueden haber continuado.

Las técnicas de recolección de información utilizadas fueron la revisión documental de comunicados de prensa y reglamentos, monitoreo de medios de comunicación digital en el periodo de la coyuntura y entrevistas semiestructuradas a actores estratégicos.

Se monitorearon los medios de mayor importancia e influencia en el país y aquellos que posicionaron el tema: el diario digital La Nación, El Financiero, El País, La República, El Semanario Universidad, Diario Extra, CentralAmericaData.com, Crhoy.com. Se analizó el contenido de cada noticia identificada con respecto a las siguientes categorías: 
Tabla 1. Categorías de análisis de contenido noticioso

\begin{tabular}{|c|c|c|}
\hline $\begin{array}{c}\text { Tipo } \\
\text { categorial }\end{array}$ & Definición & Ejemplos \\
\hline Actor & $\begin{array}{l}\text { Refiere a la persona u organización que } \\
\text { tiene una posición central o que potencia } \\
\text { el inicio de una acción. }\end{array}$ & $\begin{array}{l}\text { LAICA, MEIC, La } \\
\text { Maquila Lama S. A., } \\
\text { FEDECAÑA. }\end{array}$ \\
\hline $\begin{array}{l}\text { Dirección u } \\
\text { orientación }\end{array}$ & $\begin{array}{l}\text { Es el posicionamiento o postura a favor } \\
\text { o en contra de una persona, idea, } \\
\text { proyecto o propuesta. }\end{array}$ & $\begin{array}{l}\text { A favor, en contra, } \\
\text { neutral. }\end{array}$ \\
\hline Materia & $\begin{array}{l}\text { Énfasis, tópico central o colateral } \\
\text { señalado en el cuerpo de la } \\
\text { comunicación. }\end{array}$ & $\begin{array}{l}\text { Fortificación del azúcar, } \\
\text { dumping, competencia, } \\
\text { monopolio. }\end{array}$ \\
\hline Valores & $\begin{array}{l}\text { Se relaciona con metas (aspectos que } \\
\text { alguien desea o consigue). }\end{array}$ & $\begin{array}{l}\text { Libre competencia, } \\
\text { nacionalismo, seguridad } \\
\text { alimentaria, soberanía. }\end{array}$ \\
\hline Autoridad & $\begin{array}{l}\text { Es la persona, grupo u objeto en cuyo } \\
\text { nombre se realiza una declaración. }\end{array}$ & $\begin{array}{l}\text { Datos estadísticos, } \\
\text { UCR, MEIC, COMEX, } \\
\text { OMC. }\end{array}$ \\
\hline Métodos & $\begin{array}{l}\text { Medios empleados para los fines. Forma } \\
\text { en que los objetivos se realizan. }\end{array}$ & $\begin{array}{l}\text { Investigación, } \\
\text { negociación, opinión. }\end{array}$ \\
\hline Misión & $\begin{array}{l}\text { Refiere al grupo cuya comunicación es } \\
\text { particularmente dirigida }\end{array}$ & $\begin{array}{l}\text { A los productores de } \\
\text { caña de azúcar, a los } \\
\text { consumidores. }\end{array}$ \\
\hline
\end{tabular}

Fuente: elaboración propia con base en Berelson, Bernard 1952, citado en Abarca et al. 2012.

Las entrevistas semiestructuradas se efectuaron a actores directa e indirectamente involucrados en el conflicto. Se procuró abarcar los diversos posicionamientos con actores claves de cada actor institucional.

Tabla 2. Personas entrevistadas

\begin{tabular}{ll}
\hline \multicolumn{1}{c}{ Nombre } & \multicolumn{1}{c}{ Cargo } \\
\hline Sandoval, Juan Carlos & Gerente general de La Maquila Lama S. A. \\
Mora, Carlos Mora & Viceministro del MEIC (27 enero, 2015-8 de mayo, 2018) \\
Velásquez, Victoria & Directora de Competencia del COPROCOM \\
Arguedas, Felipe & Viceministro de MAG (1 de abril, 2016-8 de mayo, 2018) \\
Vargas, Guido & Directivo en UPANACIONAL \\
Ulate, Erick & Presidente de Consumidores de Costa Rica \\
Benavides, Henry & Coordinador de Agricultura y Contingentes, COMEX \\
Román, Luis & Presidente de UPIAV \\
Molina, Carlos & Directivo de FEDECAÑA y LAICA \\
Jenkins, Álvaro & Dueño del Ingenio EI Viejo y directivo de LAICA \\
Arias, Marvin & Representante de productores de caña de azúcar \\
\hline
\end{tabular}

Fuente: elaboración propia. 
La técnica para estudiar los datos es el análisis de coyuntura, que permite evidenciar la correlación de fuerzas entre actores. Se consideraron las categorías de acontecimientos, escenarios, actores, la relación de fuerzas, estrategias y tácticas, así como la articulación o relación entre estructura y coyuntura.

\section{Resultados y discusión}

\section{LAICA y La Maquila Lama S. A.: dos modelos de negocios}

Las dos formas de interacción entre comercio y desarrollo -el proteccionismo comercial y el libre comercio- se pueden ver reflejadas en dos modelos diferentes de negocios y de desarrollo. El primero se basa en concentrar toda la cadena de producción dentro de un mismo país, entiéndase producción, industrialización, comercialización y distribución; este requiere protegerse contra las importaciones para poder desarrollarse. Los encadenamientos productivos y la producción a pequeña escala siempre generan altos costos, lo que se traduce en sectores poco competitivos respecto a productores de escala mundial. De este modo, si bien puede haber algún nivel de exportaciones, el principal objetivo de estos sectores es el abastecimiento nacional.

En oposición a este modelo de negocios y desarrollo, tenemos uno más ligado a la liberalización comercial y a las nuevas reglas del comercio internacional. Este modelo se basa en las oportunidades de importación y la competitividad; así, se promueve todo tipo de encadenamientos a nivel internacional, involucrando corporaciones transnacionales, buscando sacar el mayor beneficio de la volatilidad de los precios mundiales. Su objetivo es aumentar la oferta de productos y ser altamente competitivos, por ende, su meta es lucrar en todas las escalas geográficas posibles. La filosofía de negocios de LAICA encapsula el modelo proteccionista, mientras que LML es reflejo del modelo de importaciones agrícolas basado en el libre comercio.

LAICA ha logrado materializar su protección en barreras como fuertes controles estatales a la importación de azúcares, liberación arancelaria para la importación de maquinaria agroindustrial para la industrialización del azúcar, el muelle para la exportación de azúcar (Punta Morales en Puntarenas) (Marchena 2016, 358).

Mediante la ley 7818, Costa Rica ha organizado su cadena de suministros del mercado azucarero en el país alrededor de los productores de caña, quienes pueden ser dependientes o independientes (los independientes que producen menos de cinco mil toneladas métricas por zafra y los no independientes, más de cinco mil toneladas métricas), y los ingenios, donde se procesa la caña para convertirla en azúcar con diferentes grados de refinamiento y venden a LAICA para su comercialización nacional e internacional (Comunicación personal, Arias 2017). LAICA es una corporación pública no estatal, con personería jurídica propia, que está al servicio de todos los ingenios y productores de Costa Rica; sus fines son la comercialización de los subproductos de la industrialización de la caña de azúcar, sea azúcar, mieles, al- 
cohol o dulces, etc. (artículos 4 y 5 de la ley 7818), bajo las marcas registradas de LAICA: Doña María, Victoria, Juan Viñas, Zukra y Natuvia.

La estructura de pagos de LAICA incentiva a los productores a mejorar sus rendimientos de azúcar por hectárea producida, lo que implica dos aspectos importantes: primero, que la calidad de la caña entregada, no la cantidad, será determinante para obtener los beneficios económicos; esto garantiza que la calidad del azúcar esté en constante mejora. Para lograr mayor rendimiento, LAICA cuenta con la Dirección de Investigación de la Caña de Azúcar (DIECA), que es una entidad especializada en investigación, innovación, mejora de variedades y asesoramiento de los productores de azúcar para optimizar sus cultivos mediante el mejoramiento de prácticas agrícolas, y combate plagas y enfermedades de la caña.

Segundo, que ningún productor tendrá la dificultad de vender la caña producida cada zafra, porque siempre se le asignará una cuota, calculada con los rendimientos de años anteriores. Existen tres escenarios posibles: que el productor no alcance la cuota asignada, que la alcance o que la supere. En caso de no alcanzarla, el faltante de cuota se distribuye entre aquellos productores que la superaron, pero el cálculo para las siguientes cuotas se verá afectado hacia la baja. Si el productor la alcanza, probablemente mantenga la misma para las próximas zafras. Si el productor supera la cuota asignada, se le irá aumentando progresivamente.

El tema del pago de cuota y extracuota es importante desde que ha constituido un argumento para criticar la estructura de LAICA por la oposición al proteccionismo, pues la caña cosechada en extracuota se paga a precios mucho menores que la cuota. Para solucionar esto, se reformó la ley 7818 el 25 de agosto de 2017; se adicionó el artículo 17 bis cuyo contenido expresa la creación del Fondo de Asistencia Económica de Productores en Régimen de Excedentes; según la Presidencia de la República, el objetivo es mitigar la diferencia entre el precio del azúcar en cuota y el precio de excedentes que puedan tener los pequeños y medianos productores de caña independientes hasta de 1500 toneladas métricas. Este fondo se sustentará con el cero coma tres por ciento $(0,3 \%)$ del precio de liquidación dentro de la cuota de la zafra que corresponda, valor crudo (Asamblea Legislativa, decreto N. ${ }^{0}$ 9466). Es decir, los ingenios y productores más grandes estarán aportando mayor cantidad de dinero para el fondo que los pequeños productores.

Para efectos de la citada contribución, únicamente se considerará a los productores independientes pequeños y medianos reales, debidamente inscritos en el Registro Nacional de Productores, y ante la comisión de zafra del correspondiente ingenio, cuyas entregas a uno o más ingenios no superen las 1500 toneladas métricas de caña. LAICA debe procurar que este fondo se entregue a los pequeños y medianos productores de caña independientes reales, debidamente inscritos en cada ingenio como productores tradicionales, y el monto de dicho fondo se distribuirá entre ellos, asignando un valor igual de compensación a cada kilogramo de azúcar entregado en régimen de excedentes, hasta un valor máximo igual al precio de liquidación del azúcar 
en cuota, si el monto del fondo así lo permitiera (Asamblea Legislativa, decreto N. ${ }^{\circ} 9466$ ).

El beneficio de esta reforma se resume en poder equiparar el precio de la extracuota a precio de cuota, pero se incluye en esta contribución solamente a pequeños y medianos productores, y existen tres grandes ingenios, El Viejo, CATSA y Taboga (todos en la zona de Guanacaste) que quedan excluidos de dicho Fondo de Asistencia Económica.

El beneficio de contar con una corporación que controla y articula todo el encadenamiento de la producción de azúcar es local. Los beneficios no son solamente para los productores y los ingenios de azúcar, sino también se articulan otros trabajadores como "transportistas, cortadores, pulperos, tiendas... estamos hablando que todo el mundo tiene que ver con esto; y que se queda localmente (la ganancia)" (Carlos Molina, comunicación personal 5 de febrero de 2018).

Por otro lado, LML es una empresa de capital costarricense, con 21 años de existencia como una maquiladora de frijoles; sin embargo, ha sufrido una evolución en el tiempo transformándose hoy en día en una compañía importadora y distribuidora de productos de canasta básica (Juan Carlos Sandoval, comunicación personal 19 de febrero de 2018). Su principal objetivo es la distribución de productos de la canasta básica y mantienen una estructura de negocios "lo más vertical posible, tratar de llegar desde el origen donde se producen los productos lo más directo hasta el consumidor base" (Juan Carlos Sandoval, comunicación personal 19 de febrero de 2018), por lo que son, en esencia, una empresa que se especializa en procesos de comercio internacional; además, está inserta en la lógica creciente de globalización de los negocios internacionales, en donde:

Las empresas latinoamericanas han pasado a ser miembros de las cadenas mundiales de suministros, ya sea a nivel de la producción o extracción de materias primas, a la producción de bienes intermedios como partes y piezas para líneas de ensamblaje o como proveedores de productos terminados a los mercados de minoristas para consumo final (Young y Esqueda 2005, 64).

Esta empresa funciona como parte de un sistema integral de la producción, industrialización, distribución y venta del azúcar como producto intermedio o de consumo final, es decir, como azúcar blanca de mesa. Pertenecer a este sistema, la hace vulnerable a interrupciones por causas externas, al igual que puede ser fuente de interrupción para otras empresas. El primer caso sucedería con un aumento o disminución de las exportaciones de azúcar en Brasil (país de origen del azúcar importada a Costa Rica), y el segundo caso es cuando el aumento o disminución de los precios del azúcar que ofrece LML al 
mercado de la industria alimentaria afecta la cadena de producción de alimentos que requieren de azúcar (Young y Esqueda 2005, 64).

Una de las diferencias más importantes entre ambas empresas, es que LML se dedica a la importación de muchos otros bienes de consumo masivo, como aceite, arroz y frijoles, por lo tanto, su prioridad no es la importación de azúcar, sino que debe ponderar el esfuerzo económico de dar cada lucha comercial, ya que tienen presente la disputa comercial por el arroz. LAICA, por otro lado, es una corporación conformada exclusivamente para la producción, industrialización, procesamiento y distribución de azúcar.

Según los argumentos expuestos por Erick Ulate, defensor del consumidor, en la conferencia en la plataforma de YouTube, "El mercado del azúcar ¿libre o monopolio", la diferencia de precios ofrecidos al mercado, entre LAICA y LML es de 20 colones por kilogramo, aproximadamente; por ello, la posible afectación económica la sufriría el industrial que requiere adquirir grandes cantidades de azúcar para fabricar otros bienes alimenticios, no así el consumidor directo de azúcar de mesa. Siendo la diferencia tan pequeña, la decisión política del conflicto debe estar dirigida hacia qué sectores beneficiar. Con la importación de azúcar, los encadenamientos que se activan son internacionales, ya que se paga a empresas productoras en Brasil, a empresas navieras para transportar los bultos de un país a otro, a industriales en países donde se llevan a cabo los procesos de refinado, como Canadá, etc.; mientras que la producción de azúcar nacional activa encadenamientos mayormente nacionales.

\section{Lucha por el mercado del azúcar}

Dos acontecimientos originan el conflicto. Para empezar, desde 2014, hubo un aumento sistemático de las importaciones de azúcar proveniente de Brasil, por parte de LML, que se plantea aumentar la oferta de productos de la canasta básica dentro de sus objetivos empresariales. Esto se considera un hito en la historia comercial del país porque, hasta ese momento, no era común que Costa Rica importara azúcar. En el país, el arancel de nación más favorecida, tal y como los que han sido definidos en negociaciones comerciales desarrolladas durante las últimas dos décadas, han definido un arancel aproximado para la importación de azúcar de un cuarenta por ciento sobre el valor del producto, incluidos costos de transporte (o ad valorem), lo que implica un claro esfuerzo de desincentivar la importación del producto.

Este aumento en las importaciones es interpretado por LAICA como una amenaza a la sostenibilidad de la producción nacional, por los precios bajos que ofrece LML al mercado, a pesar del alto arancel a la importación. El arancel para la importación de azúcar es de un $46 \%$, de tal manera que la importación de azúcar como negocio se vuelve inviable en Costa Rica. Por eso, LAICA considera la figura del dumping para interponer, en el año 2015, una denuncia por comercio desleal en la Oficina de Defensa Comercial (ODC) del MEIC. Este se convierte en el segundo acontecimiento que da comienzo al conflicto. 
Posteriormente, LML interpone una denuncia por prácticas monopolísticas relativas ante la Comisión para Promover la Competencia (COPROCOM) del MEIC, alegando que LAICA está persuadiendo a los locales comerciales para no adquirir productos Mr. Máximo, marca de LML. Las prácticas monopolísticas relativas son aquellas en las que una empresa abusa de su posición en el mercado y establecen condiciones de exclusividad a los distribuidores y vendedores (Victoria Velázquez, comunicación personal, 22 de enero de 2018).

\section{El escenario del conflicto: formal e institucional}

Desde este momento, el conflicto se concentra en los espacios institucionalizados del Gobierno. El primero es la Dirección de Defensa Comercial del MEIC. Este es un espacio para resolver conflictos de comercio internacional, el cual:

Tiene a su cargo el proceso de investigación de los procedimientos de prácticas de comercio desleal y salvaguardias. Su objetivo principal es resguardar el desarrollo productivo de las empresas a través de mecanismos que les permita protegerse ante prácticas desleales de comercio, siendo el dumping y las subvenciones los dos tipos de conductas que distorsionan el comercio internacional (Defensa Comercial MEIC, 2018).

El segundo espacio es la Comisión para Promover la Competencia (COPROCOM). La COPROCOM es un órgano de desconcentración máxima adscrito al MEIC, cuyo propósito fundamental es cumplir los preceptos de la Ley de Promoción de la Competencia y Defensa Efectiva del Consumidor N. ${ }^{\circ} 7472$, mediante la tutela y la promoción del proceso de competencia y libre concurrencia, investigando y sancionando las prácticas monopolísticas y otras restricciones al funcionamiento eficiente del mercado. Esta entidad tiene un alcance nacional y se crea para proteger al sector productivo y empresarial del país, ya que tiene como misión "la remoción de obstáculos innecesarios a la actividad productiva y el impulso de la actividad empresarial, dentro de un marco jurídico que permita el accionar y respeto de los intereses legítimos de los diversos agentes económicos" (COPROCOM, 2018).

Otras instancias involucradas son Casa Presidencial y el Ministerio de Agricultura (MAG). Primero, en Presidencia, se abre un espacio de diálogo directo entre los directivos de LAICA con el presidente de la República una vez que comienza la amenaza de importaciones de azúcar. El MAG es un escenario en el tanto se convierte en un espacio de diálogo y negociación de tácticas para proteger al sector cañero-azucarero con otras entidades, como el Ministerio de Salud y Presidencia de la República. 
Se trasladan las fuerzas en conflicto hacia la estructura política, donde se consideran recursos políticos como influencia con tomadores de decisiones; la incidencia para modificar reglamentos, decretos ejecutivos; la legitimidad de los actores políticos; la influencia con diputados y diputadas en la Asamblea Legislativa y los vínculos con Presidencia de la República. Al estar en un escenario institucionalizado y formal, el conflicto se concentra en las normas de comercio internacional establecidas por la OMC, específicamente el acuerdo antidumping, y las normas de comercio interno establecidas en la Ley de Promoción de la Competencia y Defensa Efectiva del Consumidor.

En este escenario, la capacidad de LAICA de ejecutar acciones para establecer mayor y mejor participación es amplia, ya que, desde su junta directiva, tiene participación de ministerios de Gobierno (MAG y MEIC). La larga data de su existencia le otorga legitimidad social y práctica en generar lobby político por experiencias anteriores. Por otro lado, LML es una empresa privada que no tiene la misma cercanía a poderes políticos, tampoco tiene reconocimiento social. Por lo tanto, su presencia y apoyo de la jerarquía política se reduce a aquellas entidades especializadas en promover la competencia. Por su naturaleza ideológica, esta última es una empresa que prefiere, como escenario, el mercado sin intervención estatal, una competición propia del sistema económico capitalista, ya que, en esencia, ese es el interés de LML (Comunicación personal, Victoria Velázquez, 22 de enero de 2018).

\section{Nuevos actores en la escena}

Tras la denuncia de LAICA contra las importaciones provenientes de Brasil por comercio desleal, nuevos actores entran en escena. La Alianza Nacional Agropecuaria (ANA) es una plataforma que agrupa a todo el sector agrícola costarricense, incluyendo a organizaciones como la Unión de Pequeños Productores Agropecuarios Costarricenses (Upanacional), al Consejo Nacional de Cooperativas (CONACOOP), la Cámara Nacional de Agricultura y Agroindustria, y la Unión de Productores Independientes y Actividades Varias (UPIAV). Asimismo, el ANA, colectivo que articula a productores clave del sector azucarero como las Cámaras de Productores de Caña y la Federación de Caña de Azúcar (FEDECAÑA) ofrecer el apoyo a LAICA bajo la figura legal de coadyuvantes. En julio de 2015, esta plataforma agropecuaria comunica su absoluto respaldo a la investigación por prácticas de comercio desleal presentada por el sector cañero azucarero. "No vamos a permitir que una empresa pretenda una canasta básica importada y mucho menos cuando trae producto a un precio menor del que se vende en el país de origen", afirmó Juan Rafael Lizano, presidente de la Cámara Nacional de Agricultura y Agroindustria, según el comunicado de prensa de ANA del 28 de julio de 2015.

Estos actores fungen, en la coyuntura analizada, como ayudantes al apoyar a LAICA en la denuncia contra LML por intereses homólogos; esto porque, para estos actores ayudantes, según explican Molina, Vargas, Chacón, Arguedas (2018, comunicaciones personales), lo más importante es generar un antecedente en la materia, es decir, un precedente legal, para [que], cuando una si- 
tuación similar ocurra en otro sector de la agricultura costarricense, puedan defenderse apelando a este fallo.

En el diagrama 1, se estructuran los diferentes actores involucrados en el caso, según el nivel de intervención y su posicionamiento a favor o en contra del proteccionismo comercial del mercado azucarero. El primer nivel refiere a los actores con mayor grado de involucramiento y participación directa en el conflicto; el segundo nivel, a actores que conocen y se refieren al conflicto en LAICA y LML, pero manteniendo la distancia, ya que no están directamente involucrados.

\section{Diagrama 1. Mapeo de actores y tipificación de relaciones*}

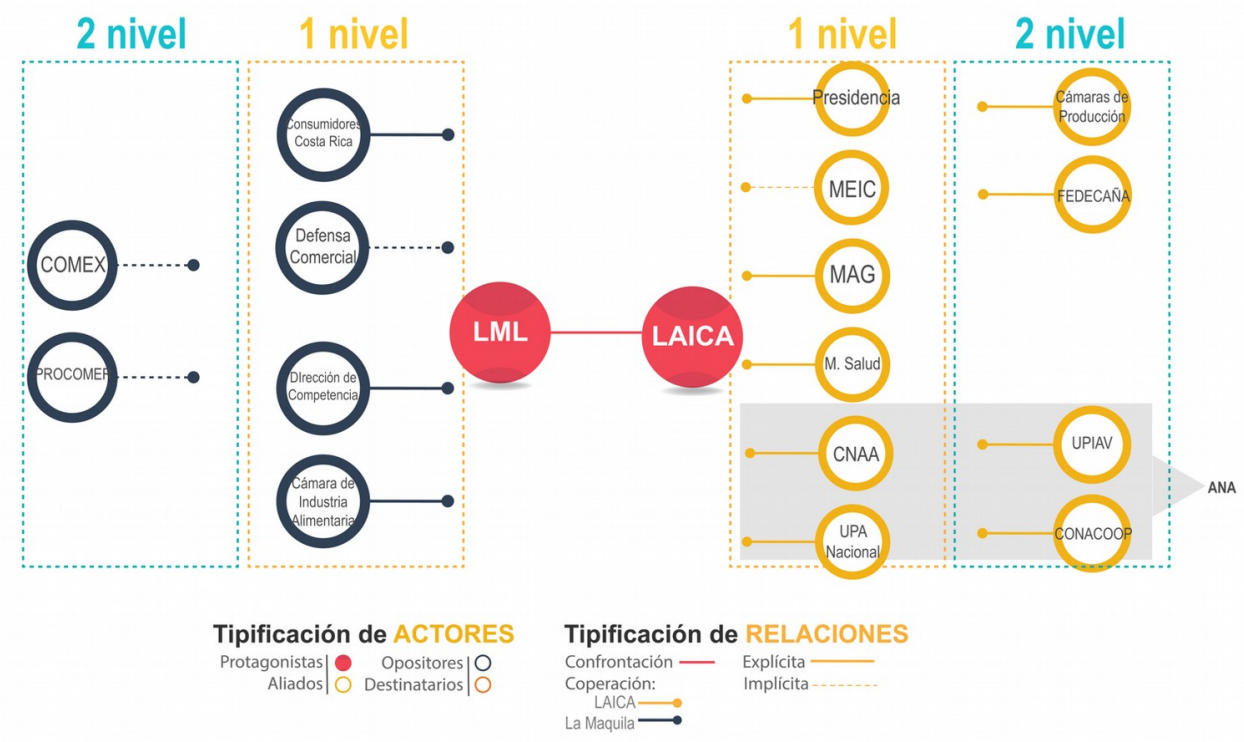

Fuente: Elaboración propia basada en entrevistas y monitoreo de noticias.

*En este estudio, se exponen las articulaciones de actores como aliados u opositores de la producción nacional como referencia analítica, es decir, aquellos denominados aliados, se entenderán que son aliados de la corriente proteccionista del producto nacional, las medidas antidumping, la soberanía alimentaria y la preservación del productor en zonas rurales. Y opositor se entenderá como aquellos actores que promueven la libre competencia, la desregulación del mercado, la desarticulación de monopolios y la liberalización de aranceles a la importación. Esto quiere decir que se hace una lectura de los acontecimientos desde el punto de vista del poder dominante, en este caso, LAICA. Esta decisión se basa en la cantidad de alianzas políticas que tiene la estructura de la Liga y el fallo del MEIC. EI conjunto de varios actores destinado a lograr objetivos compartidos se constituye como fuerza social durante la coyuntura en estudio.

El Ministerio de Salud se implica en la reforma al Reglamento técnico para la fortificación con vitamina A del azúcar blanco de plantación para el consumo directo, con Fernando Llorca, el ministro en ese momento. El Ministerio de Salud tiene potestades públicas suficientes para disponer que el azúcar importado con el fin de consumo directo venga fortificado de origen (Siu Lanzas 2015). La Cámara de Industria Alimentaria (CACIA) es otro actor involucrado 
porque compran la mayoría de azúcar a LAICA para la industria de alimentos; no importan azúcar y tampoco compran del exterior por los altos aranceles de importación. "Comprar azúcar fortificada aumenta los costos de producción, pero es un costo que la industria alimentaria asumió desde los años 80 , cuando empezó la fortificación", explicó Mario Montero, vicepresidente ejecutivo de CACIA (Siu Lanzas 2015).

Otro acontecimiento que desencadena una serie de actores involucrados es el envío de un oficio firmado por el ministro Luis Felipe Arauz, ministro de Agricultura y Ganadería, a los ministros del MEIC y Salud (oficio DM-MAG050215) solicitando que se cumplieran los acuerdos tomados en una reunión con el presidente de la República, Luis Guillermo Solís Rivera. Este acontecimiento se inscribe como una táctica de la fuerza política que procura preservar la producción, industrialización y comercialización de azúcar nacional como principal fuente de abastecimiento en el país; sin dejar de lado, la labor de lobbying directo que realiza LAICA, como grupo de presión, con el presidente de la República y ministros involucrados, ya que se efectúan gestiones legales, la denuncia por comercio desleal en la Oficina de Defensa Comercial del MEIC (ODC), pero también se establece contacto directo con las autoridades respectivas (Abarca 2012).

\section{Diagrama 2. Línea del tiempo del conflicto comercial LML y LAICA}

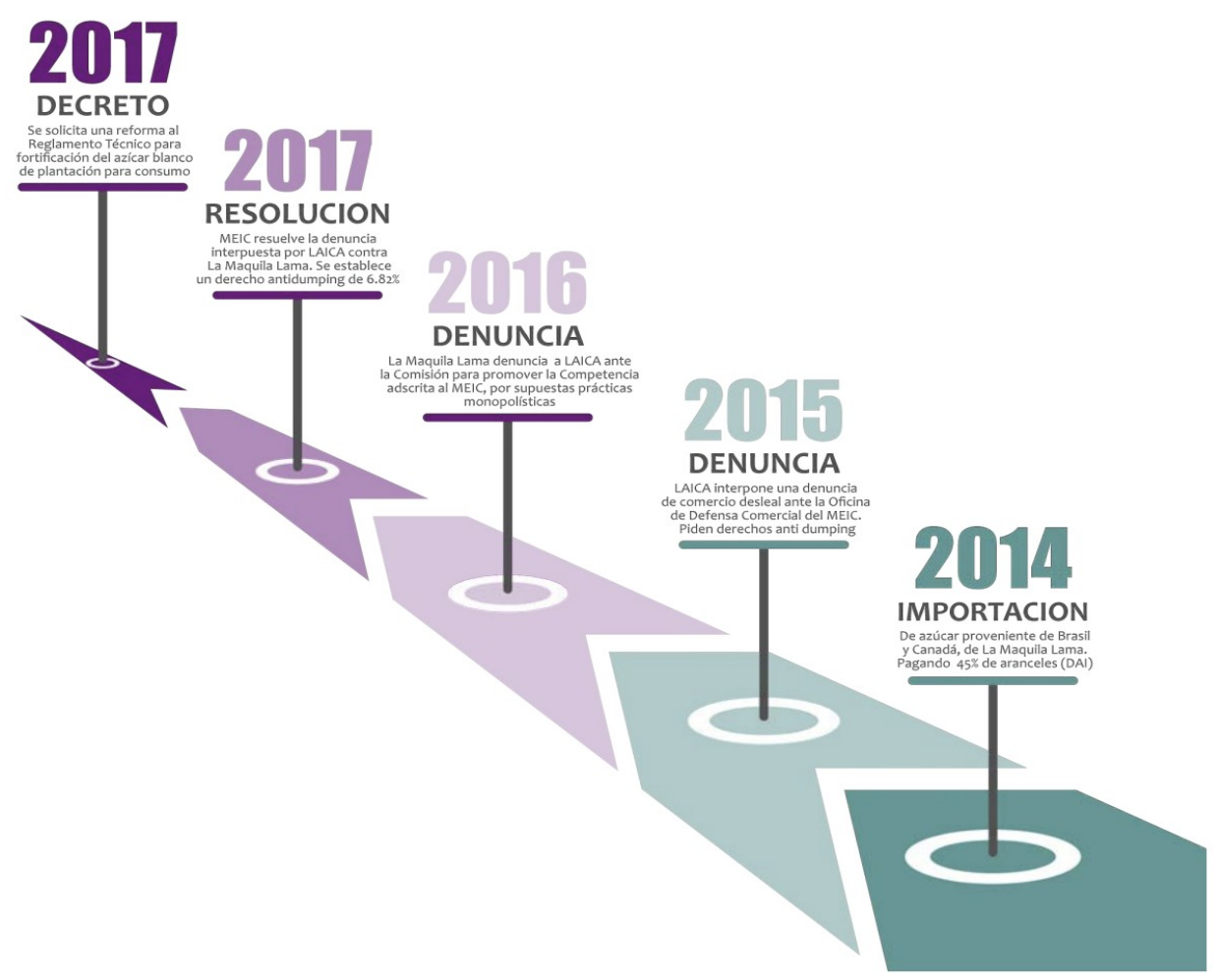

Fuente: elaboración propia a partir de revisión hemerográfica. 
El proceso para que la ODC resolviera interponer derechos antidumping comienza en el año 2014, con el aumento inusual de importaciones de azúcar a Costa Rica. Los antecedentes al fenómeno estudiado se explican en el diagrama 2.

Según los hitos históricos de los años 2015 y 2016, ambas empresas se demandan mutuamente en entidades distintas del Ministerio de Economía Industria y Comercio (MEIC). EI MEIC resuelve, en el 2017, la interposición de derechos antidumping de 6,82 \% al azúcar proveniente de Brasil, por lo que demuestra la existencia de la práctica de comercio desleal.

\section{Tácticas y estrategias}

Una vez que el MEIC resuelve a favor de LAICA con la imposición de derechos antidumping de 6,82 \% a las importaciones de azúcar provenientes de Brasil; LML, después de un periodo de estudio de la política comercial del país, toma la primera acción que podría entenderse como una táctica: enviar el azúcar de Brasil a Canadá para refinarlo en ese país, e importarlo sin pago de aranceles de Canadá bajo la figura de contingente arancelario (hasta cuatro mil toneladas métricas).

Esto se debe a que, en el tratado de libre comercio con Canadá, Costa Rica negoció un contingente arancelario de 2000 TM -que se incrementarán progresivamente durante 8 años hasta alcanzar 4000 TM- de azúcar refinado no originario (Villasuso 2010,6). Lo que significa que pueden entrar cuatro mil toneladas métricas de azúcar al país libre del impuesto a la importación, proveniente de cualquier país del mundo si primero pasa por Canadá. Álvaro Jenkins, dueño del ingenio El Viejo y miembro de LAICA, en conversación telefónica, afirma que el caso del TLC con Canadá es extraño, alega que "si nos descuidamos a la hora de firmar el contrato (...) si fue en su momento, en aquel tiempo, un descuido posiblemente de nosotros" (José Álvaro Jenkins, comunicación personal, 25 de enero de 2018).

Debido a que Canadá no es un país productor de azúcar, pero trabaja los ingenios para el refinado de azúcar, LML, en el año 2016, realiza la solicitud para importar parte del contingente de cuatro mil toneladas métricas de azúcar refino, es decir, trasladar el azúcar de Brasil hasta Canadá y, posteriormente, transportarlo hacia Costa Rica, aprovechando la preferencia arancelaria del TLC con Canadá. LAICA, después de conocer esta táctica, solicita ser parte del contingente arancelario e importa azúcar en el año 2017.

Desde el Gobierno, se articula una estrategia para frenar las importaciones de LML. Según el oficio DM-MAG-050215, se evidencian dos tácticas específicas: primero, el freno de los contenedores de azúcar de LML como una medida de emergencia ante la entrada masiva de este producto. "En algún momento nos mandaron funcionarios de LAICA a inspeccionar los primeros contenedores en puerto" (Juan Carlos Sandoval, comunicación personal, 19 de febrero de 2018). Y la segunda táctica fue la modificación al reglamento técnico de fortificación del azúcar con vitamina $A$, específicamente la eliminación del inciso b del artículo 3. 
El Reglamento técnico para la fortificación con vitamina A del azúcar blanco de plantación para el consumo directo $\left(\mathrm{N} .^{\circ}{ }^{27021-S)}\right.$ es un decreto emitido por la Presidencia de la República y el Ministerio de Salud en 1998, que pretende subsanar el déficit de vitamina A en la población preescolar y escolar, obligando a todo productor, fabricante o comerciante de alimentos cumplir con prácticas de enriquecimiento y fortificación de este componente en los alimentos habituales de la población (Reglamento Técnico N. ${ }^{\circ} 27021-S$. Considerando 4.) El artículo 3 de dicho reglamento, en los incisos a y b, expone:

El azúcar blanco de plantación que se utilice en el país para consumo humano directo deberá estar fortificado con vitamina $\mathrm{A}$.

a) La Liga Agrícola Industrial de la Caña de Azúcar asumirá la responsabilidad de la fortificación con vitamina $A$ del azúcar blanco de plantación que venda. Por su parte, los ingenios que decidan vender azúcar blanco de plantación directamente para el consumo humano directo asumen la referida responsabilidad.

b) En el caso del azúcar fortificada importada para consumo humano directo se deberá presentar el certificado de conformidad, o bien el importador será responsable de fortificar dicho azúcar con vitamina $A$ antes de ponerlo a la venta.

La táctica del MAG para bloquear la importación de azúcar fue derogar el inciso b. Esta modificación impide que la fortificación de vitamina A se realice dentro del país, lo que obliga a LML a solicitar la fortificación en la cadena de producción en la empresa brasileña, lo que, según Erick Ulate (en comunicación personal del 26 de enero de 2018), aumenta los costos para la empresa y la hace perder competitividad. En palabras de Carlos Molina, miembro de FEDECAÑA y de la junta directiva de LAICA, esta medida se utilizó porque así ellos tendrían una dificultad mayor para la importación (comunicación personal, 5 de febrero de 2018). Además, si la fortificación se efectúa en el país:

la calidad de la vitamina A no va a ser la más adecuada, mucho menos va a ser adecuada la aplicación, o sea la dosificación, porque ellos no tienen las máquinas que tenemos en LAICA; ellos nos están obligando a vitaminar 
con lo último en tecnología de aplicadores, digámoslo así, para fortificar y ellos no lo tienen; lo estuvieron haciendo en su momento hasta manualmente; en el cual quedaba la vitamina A mal distribuida (Carlos Molina, comunicación personal, 5 de febrero de 2018).

Esta táctica hace aparecer un nuevo actor en el conflicto, Erick Ulate, presidente de Consumidores de Costa Rica:

Una asociación sin fines de lucro que se fundamenta en la investigación, la promoción de la solidaridad en las relaciones que se dan entre el Estado, los consumidores, los usuarios de los servicios públicos y el comercio; así como en el activismo ciudadano en el desarrollo de una nueva cultura de consumo informada y proactiva (Consumidores de Costa Rica 2018).

Producto del conocimiento del oficio del MAG, Erick Ulate se involucra en el caso, exponiendo varias premisas desde el punto de vista de Consumidores Costa Rica. Primero, consideran que las acciones del Gobierno, específicamente las estipuladas en el oficio del MAG, son medidas que sobrepasan el poder de legalidad, es decir, "son medidas que en buena teoría no pueden tomarse sin un estudio técnico; o sea no son decisiones de política pública per se; sino que solamente se pueden tomar a partir de un estudio técnico" (Erick Ulate, conversación personal, 26 de enero de 2018).

Como segunda premisa, tienen que el incidente entre LAICA y LML es un caso particular de competencia, ya que se trasciende el tema del precio, los medios de distribución y demás aspectos meramente económicos y de mercado, para concentrarse en aspectos de definición de políticas públicas (Erick Ulate, comunicación personal, 26 de enero de 2018). Esta premisa se basa en el involucramiento de entidades públicas y de tomadores de decisiones para incidir en las dinámicas del mercado azucarero; específicamente, se refiere a la carta de enero de 2015 firmada por el ministro Felipe Arauz, "en donde se dan una serie de acuerdos, recordándole (al Ministro de Salud y Economía) los acuerdos que se dan para afectar precisamente a la competencia en el mercado" (Erick Ulate, conversación personal, 26 de enero de 2018).

Este tipo de acciones de Gobierno lesiona los principios ideológicos que sustenta la organización Consumidores de Costa Rica. En esencia, la base sustantiva de este colectivo es el libre mercado, es decir, la no intervención ni regulación del Estado en el mercado, ya que se cree en la competencia como 
medio para garantizar beneficios al consumidor. La principal disconformidad de esta organización fue el apartado 114 de la resolución N. ${ }^{\circ}$ DM-015-2017 del MEIC, en la que se conocen los recursos revocatorios interpuestos por Rigoberto Vega (apoderado legal de LAICA) y Carlos Sandoval (representante de $L M L$ ) a la resolución que impuso un 6,82 \% de derechos antidumping a las importaciones de azúcar provenientes de Brasil (resolución N. ${ }^{\circ}$ DM-0102017), es decir, los alegatos posteriores a la primera resolución del MEIC en los cuales interponía derechos antidumping al azúcar proveniente de Brasil. El apartado 114 expresa lo siguiente:

En relación con el hecho de que las exportaciones de Brasil se realizan a precios que tendrán efectos en las cotizaciones de Costa Rica, ya sea para hacerlos bajar o contener su subida de manera significativa, las variaciones interanuales del precio del azúcar en Costa Rica calculadas por el Instituto Nacional de Estadísticas y Censos muestran una tasa de crecimiento promedio de 5,7\% en el periodo de junio 2013-marzo 2015, lapso que contiene el POI. No obstante, a partir de abril 2014 y hasta agosto del 2016, esa tasa de crecimiento interanual se reduce a un promedio de 0,64 \% y muestra una tasa descendente. Por lo tanto, como se muestra en el gráfico 2, las ventas externas de azúcar blanco para uso doméstico por parte de Brasil, entre otros factores, contuvieron de manera significativa el incremento de los precios internos de Costa Rica (apartado 114 de la resolución N. DM-015-2017 del MEIC).

Este es un argumento que considera "negativo para el mercado el hecho de que los precios estén subiendo mucho menos en el mercado doméstico y que más bien los excedentes de azúcar del país tengan que venderse a precios más bajos en el exterior" (Ulate, comunicación personal, 2018). Para Consumidores de Costa Rica, es inaceptable considerar como negativo que los precios estén disminuyendo (Erick Ulate, comunicación personal, 26 de enero de 2018). Por otro lado, el argumento del MEIC consiste en afirmar que las variaciones en los precios del azúcar en Brasil están afectando las cotizaciones del azúcar en Costa Rica hacia la baja.

Esta es una disputa, a fin de cuentas, de corte ideológico, ya que dependiendo del posicionamiento político, el argumento tiene sentido o carece de este. 
Por un lado, el MEIC resolvió a favor de establecer medidas antidumping a favor de LAICA, mediante argumentos proteccionistas del pequeño y mediano productor, situación coherente con la postura que tomó el Gobierno del Partido Acción Ciudadana (PAC) con el presidente Luis Guillermo Solís, cuya base ideológica de por sí es de centro. El argumento detallado en el apartado 114 de la resolución N. ${ }^{\circ}$ DM-015-2017 del MEIC es un reflejo general del posicionamiento del Gobierno sobre este conflicto, pues basa el argumento completamente en el beneficio de los productores de caña y los industriales de azúcar. Desde ese punto de vista, es negativo que las cotizaciones de los precios del azúcar disminuyan, porque se reducen los ingresos de los productores de azúcar. Sin embargo, para Consumidores de Costa Rica, este argumento carece de sentido porque los consumidores se benefician de estas rebajas en el precio.

Marvin Arias, productor de azúcar desde hace veinte años en la zona de Pérez Zeledón, explica que no se puede valorar solamente el factor precio en la definición de políticas públicas, sino que es necesario considerar el abastecimiento a largo plazo de los bienes agrícolas. Además, expresa que "el afán de favorecer al consumidor está perjudicando al productor local porque en eso desmantela sistemas productivos; es decir, en un año puede desmantelar la producción (...); pero en este caso particular del tema del azúcar es muy sensible; por ejemplo, nosotros aquí en el cantón de Pérez Zeledón ya llevamos solo por el tema de impacto, estamos perdiendo 50 mil bultos de azúcar de 50 kg de cuota" (Marvin Arias, comunicación personal, 5 de febrero de 2018).

La medida que toma el MEIC está contextualizada en un marco legal más orientado a proteger la producción nacional de las variaciones en los precios internacionales. Carlos Mora, viceministro del MEIC manifiesta que resulta hipócrita defender las instituciones sociales del Estado y, a su vez, procurar, como consumidores, precios bajos de bienes agrícolas producidos en el país.

Los intereses de Consumidores de Costa Rica llevan a desarrollar dos tácticas específicas que responden a la estrategia de deslegitimar y exponer las actuaciones irregulares del Gobierno sobre la manera como se formula la política comercial, específicamente mediante el fallo del MEIC y las reuniones entre LAICA y Presidencia de la República. Primero, Consumidores de Costa Rica acude a la Defensoría de los Habitantes; esta instancia responde cuando alguna de las instituciones públicas no cumple correctamente con su función, puede actuar de oficio o a solicitud de parte.

La queja interpuesta se moviliza dentro de la dirección de control de la gestión administrativa, esta vía se utiliza para denunciar el mecanismo empleado por el Gobierno para modificar el reglamento de fortificación, ya que una modificación de reglamentos técnicos debe "convocar a un comité técnico de expertos con participación de mínimo de cuatro sectores, (...) tiene que tener a la academia, tiene que tener a los consumidores, tiene que tener al sector privado y al Estado" (Erick Ulate, comunicación personal, 26 de enero de 2018) y no se llevó a cabo, sino que se modificó sin ningún tipo de consulta. 
La Guía para la elaboración de Reglamentos Técnicos Nacionales expresa que en el procedimiento para hacer un reglamento técnico se debe "prestar atención especial a la participación de las partes y segmentos interesados, haciendo que se involucren en las discusiones desde las etapas iniciales del proceso" (MEIC 2015, 24). Además, esta guía explica que resulta muy importante fomentar la participación de expertos, del sector académico, de asociaciones empresariales y profesionales, de organizaciones ambientalistas, de consumidores, de trabajadores, etc. Sin embargo, estas estipulaciones las establece para la formulación de un reglamento nuevo, no sobre la modificación parcial de uno existente.

Como segunda táctica, Consumidores de Costa Rica, acude a la Procuraduría de la Ética, con el propósito de que se "investigue si la formulación de una política pública que requiere de un estudio técnico previo es válida en el tanto se toma la decisión previa a que se dé el estudio técnico" (Erick Ulate, comunicación personal, 26 de enero de 2018). En síntesis, el objetivo implícito es exponer de actos ilícitos y arbitrarios a los funcionarios del MAG, Ministerio de Salud, MEIC y Presidencia de la República.

Estas tácticas responden al lobbying gubernamental, ya que esta organización no cuenta con tanta incidencia política sobre las autoridades de Gobierno como si la tiene LAICA (Erick Ulate, comunicación personal, 26 de enero de 2018). Por esta razón acuden a instituciones de Gobierno alternativas, como la Defensoría de los Habitantes y Procuraduría de la Ética. Incluso, se excluye la posibilidad de llevar el caso a los tribunales de justicia por dos razones. La primera, por el porcentaje decretado y el impacto que este genera en el precio al consumidor, según Ulate (comunicación personal, 2018), es muy pequeño para llevar el caso. Segundo, los recursos económicos con los que cuenta esta organización son limitados, "en realidad en azúcar no tenemos procesos en los tribunales... son procesos muy caros y tampoco da para eso" (Erick Ulate, comunicación personal, 26 de enero de 2018).

Se identifican dos métodos utilizados por los grupos de presión para incidir en el caso de manera directa: la persuasión y el dinero. Con respecto al primero, Consumidores de Costa Rica mantiene una comunicación constante en todos los medios posibles, argumentando en contra de la intervención estatal en casos como el de LAICA y LML. Un ejemplo es el conversatorio organizado por el Instituto de Políticas Públicas de la Universidad Latinoamericana de Ciencia y Tecnología (ULACIT), "El mercado del azúcar ¿libre o monopolio?". También exponen los argumentos que apoyan la posición de LML en su programa radiofónico "Consumidores Activos".

\section{Intereses}

En este conflicto comercial, se pueden diferenciar dos bloques de actores respecto de sus intereses: los que están interesados en la protección del mercado azucarero a favor de la producción nacional y quienes quieren la liberalización del mercado azucarero en Costa Rica. El primer grupo está con- 
formado por el MAG, el MEIC, el Ministerio de Salud, la Presidencia de la República, LAICA, ANA, FEDECAÑA y las cámaras de productores de azúcar, que buscan proteger la producción azucarera nacional de las importaciones de azúcar provenientes de Brasil a precios bajos. En el segundo grupo se encuentra LML, Consumidores de Costa Rica, La Cámara de Industria Alimentaria (CACIA) y la COPROCOM del MEIC, abiertamente posicionados a favor de la liberalización arancelaria y desregulación del mercado azucarero. CACIA ha manifestado la solicitud de "eliminación (...) de las distorsiones presentes en la comercialización de sus principales materias primas, siendo el azúcar una de las primordiales y más importantes" (CentralAmerican Data 2011).

Las autoridades de LAICA apuestan por una competencia llamada sana, es decir, "con reglas claras y no en mercados de excedentes que son precios mucho menores a sus mercados locales" (José Álvaro Jenkins, comunicación personal, 25 de enero de 2018); por lo que la institución niega la posibilidad de competir con los exportadores mundiales, la definición de competencia establecida por estos implica un cierto tipo de paridad o equidad, consideran que se debe competir entre iguales, ya que "si te ponen a competir con alguien que es un monstruo y además de eso manda al mercado mundial a precio menor del que vende en su mercado local; es una competencia desleal y es imposible competir contra eso y te quiebran" (Álvaro Jenkins, comunicación personal, 25 de enero de 2018).

El interés principal de LAICA es mantenerse unida frente a las amenazas de desarticulación:

Simplemente lo que tenemos es una ley donde nos hemos puesto de acuerdo el sector azucarero para ahorrar costos y ser más eficientes; tenemos empaques en conjunto, tenemos una distribución en conjunto, pero eso no quiere decir que seamos monopolio o mucho menos, simplemente es algo que hemos tenido un acuerdo. Así que más bien el esfuerzo para todo el mundo se sienta contento dentro de la organización que estamos representando y estar haciendo una buena labor y mantener al sector unido (José Álvaro Jenkins, comunicación personal, 25 de enero de 2018).

Para poder lograrlo, consideran inviable la posibilidad de que en el país se comience a importar azúcar de cualquier parte del mundo, dado que los precios internacionales son muy bajos porque la estructura productiva y los costos de producción se dan en condiciones muy diferentes a las nacionales. 
A LML, le interesa competir en el mercado de granos básicos importados en Costa Rica, colocar en el mercado otra marca de azúcar que compita con la marca Doña María de LAICA. A la vez, le interesa disminuir el control sobre el mercado azucarero para que le precio esté definido por las fuerzas del mercado, la correlación entre oferta y demanda, y no por una sola entidad, como supuestamente está determinado actualmente. A pesar de ser la primera empresa que importa azúcar para competir con LAICA, LML no está en contra de la estructura de esa organización, sobre todo, está consciente de que:

cualquier reducción drástica en las ven las ventas o en sus costos automáticamente va a golpear a los productores medianos y pequeños que han vivido del tema del azúcar y que hay que tenerlo mucho ahí; agricultores de muchas zonas, de Grecia, San Ramón que vos vas a ir a entrevistar y con cuatro o cinco, seis hectáreas han podido tener un nivel de clase media interesante, han sacado avante a sus hijos en las universidades; y eso en un esquema de nivel de competencia global no se puede sostener. Hoy es imposible competir con países que tienen economías de escala de 5000, 15 000, 30000 hectáreas contra un modelo como el que tiene Costa Rica de pequeños productores de cuatro o cinco hectáreas (Juan Carlos Sandoval, comunicación personal, 19 de febrero de 2018).

El interés de LML es buscar un punto donde pueda coexistir la producción nacional con la importación y el centro sea el consumidor como una parte que no se vea afectada.

Consumidores de Costa Rica defiende la libertad de elección del consumidor, estipulada en la esolución 39/248 del 4 de abril de 1985 de la Organización de las Naciones Unidas (ONU) que determinan que "el gobierno debe alentar la competencia leal y efectiva a fin de brindar a los consumidores la posibilidad de elegir productos y servicios dentro del mayor surtido y a los precios más bajos" (UNCTAD, 2001).

Este colectivo considera que las acciones de las autoridades públicas no son imparciales, ya que atentan la economía de los consumidores en contra la libertad de elección, por el bloqueo comercial a las importaciones de LML estipulado por las medidas antidumping de la resolución del MEIC, la salvaguarda a las importaciones de azúcar y, en sí mismo, el arancel $\mathrm{NMF}^{4}$ establecido

4. Se refiere al principio de la OMC de Nación Más

Favorecida. Ver más en OMC, Nación Más Favorecida:

https://www.wto.org/spanish/tra top_s/serv_s/cbt_course_s/c1s 
del azúcar. De esta manera, el interés explícito de esta organización es garantizar una amplia variedad de productos, que compitan entre sí y se ofrezcan a precios bajos; el interés implícito es reducir la intervención del Gobierno en las dinámicas del mercado, desde eliminar todo tipo de impuestos y aranceles hasta desbloquear las trabas administrativas para el comercio. Además, Consumidores de Costa Rica tiene claro lo que no le interesa:

las relaciones con el agricultor, las relaciones con el industrial, las relaciones con el importador, no son resorte nuestro y no nos importa, o sea que entre ellos tienen problemas porque se prestan plata, que no se pagan porque se compran muy bajo o se compran muy alto, o sea es algo que no nos interesa; si el productor sobrevivió o no sobrevivió nosotros nos lavamos las manos, porque no nos interesa; nos interesa el tema del Consumidor, nos interesa el precio bajo el cual el consumidor compra el producto (Erick Ulate, comunicación personal, 26 de enero de 2018).

El interés de la Comisión para Promover la Competencia (COPROCOM) es generar competencia en el mercado del azúcar, ya sea entre los productores nacionales o producto de las importaciones, para evitar que el precio del bien lo defina arbitrariamente una sola empresa. Asimismo, para la Cámara de Industria Alimentaria es favorable la competencia de proveedores de azúcar, porque esto provocaría mayor variedad de precios y un aumento en la calidad del bien. Lo que, al final, implicaría una baja en los costos de producción, aumento de la rentabilidad empresarial y mayor competitividad en el mercado con los productos alimenticios.

Para Carlos Mora, viceministro del MEIC, "no se vale destruir una industria nacional porque otro país tuvo una sobreoferta; que no necesariamente va a ser siempre; cuando el azúcar suba de precio y nosotros no tengamos producción nacional... ¡nos pasó con frijol! Casi que todo el frijol que se consume en el país viene importado" (Carlos Mora, comunicación personal, 30 de enero de 2018). Se analiza, desde estas figuras de autoridad, la sostenibilidad a largo plazo de esas importaciones y, por otro lado, la destrucción de una producción imposible de reanimar, como explica Marvin Arias, "cuando se quiera regresar a las tierras, ya estarán ocupadas" (Marvin Arias, comunicación personal, 5 de febrero de 2018).

La industria agrícola no puede analizarse bajo los mismos parámetros económicos que cualquier otra industria, pues tiene particularidades que la hacen diferente y sensible. Es diferente porque quienes trabajan la tierra, tienen un vínculo especial con ella, "Nosotros no producimos, inducimos a la tierra a 
hacerlo" (Marvin Arias, 5 de febrero de 2018). Por lo tanto, sin tierra disponible, es imposible que exista la agricultura, a diferencia de muchas industrias que no requieren de tierras, condiciones climáticas particulares, condiciones químicas y orgánicas del suelo, temperatura y humedad.

El posicionamiento del viceministro del MEIC, explícitamente, es a favor de proteger la producción nacional y del productor agrícola, dejando de lado el argumento de protección al consumidor, ya que:

(...) somos unos grandes hipócritas; y grábamelo... somos unos grandes hipócritas cuando decimos es que yo quiero arroz, frijoles y azúcar y todos esos productos de la canasta básica más baratos porque vienen de otro país y son más baratos porque aquí pagamos cargas sociales, tenemos salarios mínimos, tenemos seguridad social... (Carlos Mora, comunicación personal, 30 de enero de 2018).

Los intereses del MEIC, además de garantizar mesura en los precios al consumidor, también se enfocan en procurar un consumo responsable de productos nacional, en el tanto se conozcan las condiciones sociales de producción de cada bien (esclavitud, condiciones laborales, malos tratos, pobreza).

Para Felipe Arguedas, viceministro del MAG, desde esta instancia de Gobierno se procura defender la producción nacional, que el azúcar que se consuma a nivel nacional sea costarricense y que el agricultor se mantenga en las zonas rurales produciendo azúcar (Felipe Arguedas, comunicación personal, 19 de enero de 2018). Se considera, desde esta autoridad gubernamental, que el fallo del MEIC es importante, pues, una vez que el Estado decreta el caso de dumping acertado y da el aumento arancelario, genera un antecedente importante que va creando experiencia en este tipo de casos comerciales; además, deja al país con la imagen de defensa comercial. El principal interés del MAG como ministerio es trabajar para que los productores aumenten sus rendimientos y puedan ofrecer precios justos al mercado, el respeto por el ambiente, el uso de agroquímicos de forma racional para obtener un producto con la mayor inocuidad posible. "Además, procurar el azúcar no solo de hoy ni mañana, sino de entre cinco o diez años" (Felipe Arguedas, comunicación personal, 19 de enero de 2018).

\section{Conclusiones}

El conflicto por dumping entre LML y LAICA ocasiona el despliegue de tácticas y estrategias políticas que demuestran el ejercicio del poder político y económico de estas corporaciones, lo cual evidencia dinámicas contradictorias con los principios del desarrollo basado en crecimiento económico y libre 
comercio como, por ejemplo, la filosofía individualista, la propiedad privada, la evolución económica, la garantía de la competencia y la supervivencia del más fuerte.

El comportamiento político de ambas empresas en este conflicto refleja que las dos perspectivas económicas, la proteccionista y el librecambrismo, confluyen y se instauran dentro del mismo sistema económico en diferentes niveles de la institucionalidad costarricense.

Por ejemplo, el estatuto orgánico de LAICA resguarda los intereses económicos de los pequeños, medianos y grandes productores, evitando la competencia individual entre ellos, no existe dentro de esta estructura el principio del librecambismo de la competencia por el mercado ni la supervivencia del más fuerte. Este sistema de funcionamiento en LAICA articula una dimensión solidaria con los pequeños productores que, desde la visión política estrictamente neoliberal, se considera una distorsión al mercado, ya que solo deberían permanecer aquellos empresarios suficientemente eficientes.

LAICA protege el sistema de producción, industrialización y comercialización del azúcar que ha logrado instaurar con la participación de pequeños, medianos y grandes productores e ingenios de azúcar. Sin embargo, no descarta el principio del libre comercio hacia afuera del territorio nacional, ya que mantiene fuertes vínculos comerciales con Estados Unidos y Europa para la exportación de azúcar (Molina, Jenkins, Arias, comunicación personal 2018).

A fin de cuentas, este comportamiento político evidencia la necesidad de LAICA de mantener los pactos y acuerdos políticos logrados a lo interno del país, en las diferentes esferas y arenas políticas, es decir, tanto el acuerdo de protección comercial con ministerios como el pacto logrado entre todos los productores e ingenios del país.

El conflicto comercial de dumping resultó un hito histórico porque el sector cañero-azucarero en Costa Rica ya mantenía un conjunto de valores y reglas de comportamiento bien estructurados que vinculaban instituciones públicas y privadas.

Sin embargo, se concluye que ambos modelos económicos, proteccionismo y librecambismo, identificados respectivamente con LAICA y LML, confluyen en el sistema económico con un cierto grado de equilibrio, evitando el extremo de alguna de las dos perspectivas económicas, porque el comportamiento político de LML es estricto con respecto a los valores del principio del libre comercio del sistema económico capitalista.

La competencia, desde esta perspectiva, se considera la base para alcanzar la justicia social y el sistema de precios como herramienta de asignación de recursos productivos, lo que no puede contradecirse, ya que el monopolio de un mercado en pocas manos, por definición, conseguiría probablemente abusos de poder y distorciones económicas. Por lo eso, LML en términos económicos, vendría a ser la balanza en el mercado azucarero, es decir, la garantía de la competencia por el mercado del azúcar en Costa Rica. 
Una de las contradicciones evidentes en el estudio de este caso fue el uso estratégico y político de las herramientas de comercio internacional disponibles desde las instituciones públicas. Por ejemplo, la definición de comercio desleal procura evitar que existan actitudes comerciales tendientes a dominar monopólicamente un mercado. Es irónico, en este caso, que la corporación que domina un mercado usa las herramientas institucionales para contrarrestar el comercio desleal.

La conclusión académica más importante respecto de lo anterior es que se debe interpretar el comportamiento político de los agentes individuales y colectivos, según contextos históricos (de carácter socioeconómico e institucional), los agentes y sus formulaciones, opciones, tácticas, y conductas políticas. No se debe aislar el comportamiento político de actores sociales de su realidad y contexto histórico.

Esta investigación plantea la necesidad de continuar estudiando el funcionamiento e implicaciones del sistema económico capitalista, sus diferentes formas, tendencias y modalidades de actuación. Máxime las implicaciones de los modelos de dominación y subordinación en los países latinoamericanos y, sobre todo, en la calidad de vida de las personas.

Esto porque la subordinación y la dependencia de los países "subdesarrollados" se materializa en las relaciones de poder desiguales del juego del sistema multilateral del comercio, puesto que el único factor relevante para determinar la competitividad y eficiencia de una empresa o sector es el precio de la mercancía, independientemente de dónde y cómo se produce. Esto invisibiliza las consecuencias políticas, ambientales, laborales y sociales de la producción agrícola en los países lationamericanos. Estas nuevas categorías de análisis son las que se proponen para continuar el diálogo y el acercamiento a la comprensión de tales fenómenos políticos con futuras investigaciones.

\section{Bibliografía}

Abarca, Allan, Felipe Alpízar, Gina Sibaja y Carla Rojas. 2012. Técnicas cualitativas de investigación. San José: Editorial UCR, 2012.

Agosin, Manuel y Diana Tussie. 1993. Trade and Growth: New Dilemmas in Trade Policy -- An Overview. Ch. 1 in Trade and Growth: New Dilemmas in Trade Policy, St. Martin's Press.

Asamblea Legislativa de la República de Costa Rica. 1998. Ley 7818, Ley Orgánica de la Agricultura e Industria de la Caña de Azúcar. 22 de setiembre de 1998. 
Asamblea Legislativa de la República de Costa Rica. 2017, agosto 25. Decreto Legislativo $N^{\circ}$ 9466, expediente $N^{\circ}$ 20.245. Reforma de varios artículos de la ley N. ${ }^{\circ} 7818$, Ley Orgánica de la Agricultura e Industria de la Caña de Azúcar, de 2 de setiembre de 1998.

Castro, Jorge. 2018, mayo 2. "Aumentan los subsidios al agro en el mundo avanzado". Diario Clarín.

Chang, Ha-Joon.2003. "Patada a la escalera: La verdadera historia del libre comercio". Conferencia en la Facultad de Ciencias Económicas y Ciencias Políticas de la Universidad de Cambridge.

Consumidores de Costa Rica. 2018. Consumidores de Costa Rica. Defensa del Consumidor. Disponible en http://www.consumidoresdecostarica.org/quienes_somos.html.

COPROCOM. 2018. Comisión para Promover la Competencia. Disponible en www.coprocom.go.cr

Cuadrado, Juan R., Tomás Mancha, José E. Villena, Javier Casares, Miguel González, José María Marín y María Luisa Peinado. 2010. Política económica: elaboración, objetivos e instrumentos. Editorial McGrawHill. 4. ${ }^{\text {a }}$ edición

Defensa Comercial. 2018. Ministerio de Economía, Industria y Comercio. Disponible en https://www.meic.go.cr/meic/web/47/defensacomercial.php

Fernández, Mario. 2004. La agricultura costarricense ante la globalización. Las nuevas reglas del comercio internacional y su impacto en el agro. San José: Editorial de la Universidad de Costa Rica. Instituto de Investigaciones Sociales, 2004.

Krugman, Paul. 1987. "Is Free Trade Passé?" Journal of Economic Perspectives 1(2).

La Maquila Lama. ¿Quiénes somos? Disponible en http://www.maquilalama.com

LAICA. 2017. "MEIC impone derechos antidumping." Resolución del MEIC da la razón a sector cañero-azucarero costarricense. 
LAICA. 2017. Liga Agrícola Industrial de la Caña de Azúcar. Disponible en https://www.laica.co.cr

MAG. 2015. Oficio Ministerio de Agricultura y Ganadería DM-MAG-050215, firmado por el ministro Luis Felipe Arauz.

Marchena, Jorge. 2016. "Las alianzas del azúcar y la política: apuntes para la comprensión histórica de la élite azucarera en Costa Rica (1950-2010)". Anuario de Estudios Centroamericanos. Vol. 42:357-383. Universidad de Costa Rica, San José, Costa Rica.

MEIC. 2010. Comisión para promover la competencia. Expediente. Investigación sobre el Mercado de Azúcar LAICA. IO-007-01. Disponible en http://comerciouna.wikispaces.com/file/view/Investigaci \%C3\%B3n\%20sobre\%20el\%20Mercado\%20de\%20Az\%C3\%BAcar. \%20MEIC.pdf/348186292/Investigaci\%C3\%B3n\%20sobre\%20el \%20Mercado\%20de\%20Az\%C3\%BAcar.\%20MEIC.pdf

MEIC. 2015. Guía para la elaboración de reglamentos técnicos nacionales. Sistema Nacional para la Calidad.

MEIC. s. f. Ministerio de economía, industria y comercio. Disponible en http:// www.meic.go.cr

Mujica, Norbis y Sorayda Rincón. 2010. "El concepto de desarrollo: posiciones teóricas más relevantes". Revista Venezolana de Gerencia 15(50): 294-320.

Nava, Juan, Carlos Galperín y Verónica Fossati. 2011. "La crisis económica y el proteccionismo agrícola". Revista del CEI 19.

ODEC. 2018. Organizaciones de Consumidores. Disponible en https://www.consumo.go.cr/tramites_servicios/ODEC.aspx

OMC. 2018. Organización Mundial del Comercio. Disponible en https://www.wto.org/indexsp.htm

OMC. s.f. La OMC y el sistema multilateral de comercio. Módulo 1. Disponible en https://ecampus.wto.org/admin/files/Course_419/Module_2120/Module Documents/NAMA-M1-R1-S.pdf 
Presidencia de la República, Ministerio de Salud. 1998. Reglamento técnico para la fortificación con vitamina A del azúcar blanco de plantación para el consumo directo (N. $\left.{ }^{\circ} 27021-\mathrm{S}\right)$.

PROCOMER. 2016. Anuario estadístico. San José.

PROCOMER. 2018. Servicios. Estadísticas PROCOMER. Disponible en http://servicios.procomer.go.cr/estadisticas/inicio.aspx

Rosales, Osvaldo. 2009. La globalización y los nuevos escenarios del comercio internacional. Revista CEPAL 97, 77-95. Obtenido en línea de:

https://repositorio.cepal.org/bitstream/handle/11362/11272/097077095 es.pdf? sequence=1\&isAllowed=y

Shaikh, Anwar. 2004. The economic mythology of neoliberalism. London: Pluto Press.

Siu Lanzas, María. 2015, noviembre 4. "Industria Alimentaria deja en evidencia a Ministerio de Salud". Diario digital Crhoy.com. Disponible en http://www.diarioextra.com/Noticia/detalle/275018/industria-alimentaria-

Stiglitz, Joseph. 2002. Globalization and its Discontents, W. W. New York: Norton and Company.

Sunkel, Osvaldo. 1994. La crisis social de América Latina: Una perspectiva neoestructuralista. En Contreras Quina, Carlos. (Compilador). El desarrollo Social. Tarea de todos. Comisión Sudamericana de Paz, Seguridad y Democracia. Caracas: Editorial Nueva Sociedad, Primera Edición.

Ulrich, Klaus. 2017, setiembre 28. "La UE pone fin a subvenciones del azúcar." Diario DW. Disponible en http://www.dw.com/es/la-ue-pone-fina-la-subvención-del-azúcar/a-40736054

UNCTAD. 2001. Directrices de las Naciones Unidas para la Protección del Consumidor. (Ampliación de 1999).

UNICEF. 2003. Libre comercio e infancia. Disponible en https://www.unicef.org/lac/Libre_Comercio_e_Infancia(11).pdf

Villasuso, Juan Manuel. 2010. "El tratado de libre comercio entre Canadá y Costa Rica". Red Latinoamericana de Política Comercial. Flacso. 
Young, Richard y Paul Esqueda. 2005. "Vulnerabilidades de la cadena de suministros: consideraciones para el caso de América Latina". Revista Latinoamericana de Administración. Vol34: 63-78. Disponible en http://www.redalyc.org/pdf/716/71603405.pdf 